\title{
Penanaman Karakter Peduli Lingkungan Siswa SMP N 2 Gatak Menuju Sekolah Adiwiyata
}

\author{
Dewi Tiara Pratiwi $\left.{ }^{*}\right)$, Isnaini Nurlia Sapitri2), Suharyadi Wibowo ${ }^{3)}$, \\ Yeni Prastiwi4) \\ 1,2,3,4)Universitas Muhammadiyah Surakarta \\ *a420170072@student.ums.ac.id
}

\begin{abstract}
Abstrak: Lingkungan mempunyai peran penting bagi manusia karena dapat menunjang kehidupan manusia baik secara langsung maupun tidak langsung. Lingkungan harus dijaga dari kerusakan oleh semua pihak tanpa terkecuali. Pihak sekolah merupakan salah satu pihak yang berperan penting dalam menanamkan karakter peduli lingkungan pada siswa. SMP N 2 Gatak menanamkan karakter peduli lingkungan melalui berbagai kegiatan yang berhubungan dengan lingkungan. Tujuan penelitian ini adalah untuk mengetahui bagaimana penanaman karakter peduli lingkungan pada siswa dan persiapan SMP N 2 Gatak menuju sekolah Adiwiyata. Metode penelitian ini yaitu deskriptif dengan menggambarkan dan menjelaskan permasalahan dalam bentuk teks, yang dilaksanakan di SMP N 2 Gatak melalui kegiatan PLP I dalam waktu pelaksanaan selama 2 minggu. Teknik pengumpulan data dilakukan dengan cara observasi partisipatif yaitu mengumpulkan data-data dari pengamatan langsung dan wawancara kepada narasumber. Hasil penelitian ini menunjukan bahwa dengan adanya program Adiwiyata dapat meningkatkan karakter peduli lingkungan pada siswa SMP N 2 Gatak.
\end{abstract}

Kata kunci : Peduli Lingkungan, Adiwiyata

\section{PENDAHULUAN}

Kepedulian terhadap lingkungan merupakan tanggung jawab semua orang. Hal ini disebabkan oleh perilaku manusia yang kurang memperhatikan lingkungan sehingga semakin hari kualitas lingkungan semakin menurun. Penurunan kualitas lingkungan ini terjadi karena tindakan eksploitasi berlebihan terhadap alam tanpa memperhatikan daya dukung lingkungan dan fungsi ekologinya, yang mengakibatkan kekhawatiran di masa depan bagi makhluk hidup. Manusia selalu berusaha untuk mendapatkan kenyamanan hidup yang berdampak pada tindakan eksploratif (Rahmawati, 2015). Perilaku manusia adalah faktor utama penyebab kerusakan lingkungan hidup, banyaknya kerusakan lingkungan yang diakibatkan oleh faktor antropogenik mendorong adanya upaya untuk melakukan perbaikan lingkungan (Iswari, 2017). Seiring adanya permasalahan lingkungan yang semakin komplek maka kepedulian lingkungan harus ditanamkan pada semua orang melalui pembiasan memelihara kebersihan lingkungan.

Sekolah merupakan salah satu tempat untuk menanamkan sikap peduli lingkungan terutama pada siswa. Pendidikan adalah salah satu variable paling penting dalam membentuk perilaku peduli lingkungan (Iswari, 2017). Pembiasaan peduli terhadap lingkungan dapat diimplementasikan pada lingkungan masyarakat maupun sekolah. Kegiatan peduli lingkungan dapat dilakukan dengan cara menjaga lingkungan sekolah, menjaga kebersihan kelas, membuang sampah 
pada tempatnya, memanfaatkan barang barang bekas untuk kerajinan, menyediaan peralatan kebersihan, serta pembuatan program pendidikan lingkungan hidup. Pendidikan lingkungan yang dilakukan oleh sekolah dapat membentuk karakter peduli lingkungan pada siswa. Pembentukan karakter ini tentu melalui proses yang dilakukan berulang-ulang dengan di dukung lingkungannya (Adrianti, 2017:1).

Pembentukan karakter peduli lingkungan yang diajarkan sejak dini akan berpengaruh positif pada karakter siswa di masa depan. Karakter dapat diartikan sebagai watak, tabiat, akhlak dan kepribadian seseorang yang terbentuk dari hasil internalisasi berbagai kebijakan yang digunakan sebagai landasan cara pandang, cara berpikir, bersikap dan bentindak (Al-Anwari, 2014). Sedangkan menurut Widyaningrum (2016) karakter merupakan jati diri yang ada pada setiap individu. Karakter peduli lingkungan terhadap alam merupakan sikap yang ditunjukan dengan perbuatan menjaga lingkungan alam sekitarnya. Sikap ini juga ditunjukan dengan memperbaiki kerusakan lingkungan yang terjadi (Harlistyarintica, 2017:22). Karakter ini terbentuk bukan hanya melalui pembiasaan saja, tetapi juga bisa melalui pembuatan kebijakan sekolah yang mengintegrasikan pendidikan lingkungan hidup dalam kurikulumnya (Bahrudin, 2017:27).

Pendidikan lingkungan hidup di sekolah perlu diperhatikan karena sekolah merupakan tempat untuk membentuk karakter siswa. Pendidikan lingkungan di sekolah dapat menyadarkan siswa akan pentingnya nilai peduli lingkungan bagi kehidupan. Pada dasarnya masih banyak kerusakan lingkungan yang disebabkan oleh siswa itu sendiri. Kepedulian lingkungan akan berdampak di lingkungan masyarakat (Lestari, 2018:332). Melalui proses belajar mengajar yang bermuatan pendidikan lingkungan hidup dapat meningkatkan kesadaran siswa, mengarahkan, membimbing dan membentuk etika dalam menjaga lingkungan (Mulyana, 2009). Pendidikan lingkungan hidup perlu dilakukan sebagai kesempatan yang diberikan pada siswa untuk menambah pengetahuan dan menumbuhkan kepedulian dalam upaya memperbaiki kualitas hidup yang bersahabat dengan alam dan lingkungan (Nurani, 2014). Sedangkan menurut Adam (2014) pendidikan lingkungan dilakukan lebih sebagai upaya untuk meningkatkan pemahaman dan kepedulian masyarakat dan lebih berorientasi pada mencari pemecahan dan pencegahan timbulnya masalah lingkungan.

Kementrian lingkungan hidup mengeluarkan keputusan No. 5 Tahun 2013 tentang program lingkungan hidup pada jenjang pendidikan dasar dan menengah melalui program Adiwiyata. Program Adiwiyata merupakan salah satu program Kementrian Negara Lingkungan Hidup dalam rangka mendorong terciptanya pengetahuan dan kesadaran warga sekolah sehinga menjadi sebuah karakter peduli lingkungan dalam upaya pelestarian lingkungan hidup (Azmi, 2017:126). Program ini bertujuan untuk mendorong dan membentuk 
sekolah-sekolah di Indonesia agar dapat turut melaksanakan upayaupaya pemerintah menuju pelestarian lingkungan dan pembangunan berkelanjutan bagi kepentingan generasi sekarang maupun yang akan datang (Adam, 2014). Tujuan ini selaras dengan tujuan strategis sekolah Adiwiyata menurut Landriany (2014) yaitu 1) tersedianya layanan pendidikan karakter yang memadai dan terjangkau; 2) terjaminnya pendidikan lingkungan hidup; 3) tersedia dan terjaminnya mutu pembelajaran yang berkelanjutan dan relevan dengan kebutuhan era global; 4) sistem manajemen yang handal dalam menjamin terselenggaranya layanan pendidikan; dan 5) terjaminnya pendidikan ramah lingkungan.

SMP N 2 Gatak merupakan sekolah yang sedang melakukan persiapan menuju sekolah Adiwiyata. Sekolah Adiwiyata merupakan sekolah ideal untuk memperoleh ilmu pengetahuan, norma dan etika yang dapat menjadi dasar kehidupan sejahtera dan cita-cita pembangunan yang berkelanjutan (Anonim dalam Mulyana, 2009). Persiapan yang dilakukan antara lain yaitu dengan cara melakukan penanaman karakter peduli lingkungan pada siswa dengan memberikan tanggung jawab kepada siswa untuk merawat tanamannya yang dibawa dari rumah dan menjaga lingkungan sekolah, menyediaan sarana dan prasarana yang mendukung terjaganya lingkungan sekolah, adanya proses pembelajaran di luar kelas untuk meningkatkan kepedulian lingkungan pada siswa, serta impelemtasi peduli lingkungan melalui kebijakan sekolah meliputi visi sekolah yang mendukung peduli lingkungan. Implementasi pendidikan lingkungan hidup di sekolah adiwiyata dapat dilakukan secara monolitik dan terintegrasi dengan mata pelajaran wajib (Aini, 2014).

Adapun visi SMP N 2 Gatak yaitu "Berakhlak Mulia, Unggul dalam Prestasi, Berwawasan Lingkungan Berlandaskan Iman dan Taqwa”. Namun dalam praktiknya, berbagai persiapan yang dilakukan SMP N 2 Gatak menuju sekolah Adiwiyata tidak selalu berjalan lancar. Beberapa siswa masih ada yang merusak sarana prasarana yang telah disediakan dan tidak ikut serta dalam menjaga lingkungan sekolah. Oleh karena itu, penelitian ini dilaksanakan dengan tujuan meningkatkan sikap peduli lingkungan siswa SMP N 2 gatak menuju sekolah Adiwiyata melalui berbagai kebijakan sekolah sehingga terbentuk karakter peduli lingkungan pada siswa yang akan bermanfaat di masa yang akan datang. Dengan terbentuknya karakter peduli lingkungan disekolah, diharapkan siswa dapat lebih mengenal alam dan peduli terhadap alam sehingga tidak merusaknya serta senantiasa menjaga kelestariannya.

Penelitian ini bertujuan untuk menanamkan karakter peduli lingkungan pada siswa SMP Negeri 2 Gatak menuju sekolah adiwiyata melalui penanaman pohon pada area sekolah dan pemanfaatan barang bekas menjadi kerajinan yang mendukung tata kelola lingkungan sekolah. 


\section{METODE}

Penelitian ini dilakukan pada saat kegiatan PLP I yang diadakan oleh Laboratorium Microteaching FKIP UMS yang dimulai dari tanggal 29 Januari 2019 sampai dengan tanggal 11 Februari 2019 di SMP Negeri 2 Gatak. Pembuatan artikel membutuhkan waktu selama dua minggu. Penelitian ini menggunakan metode deskriptif dengan menggambarkan dan menjelaskan permasalahan dalam bentuk teks. Metode ini dapat memberikan gambaran persiapan SMP Negeri 2 Gatak menuju sekolah adiwiyata dengan harapan terbentuk karakter peduli lingkungan pada siswa. Teknik pengumpulan data dilakukan dengan cara observasi partisipatif yaitu mengumpulkan data-data dari pengamatan langsung dan wawancara kepada narasumber. Narasumber penelitian ini adalah ibu Inggit C.A, S.Pd bagian sarana dan prasarana SMP N 2 Gatak. Analisa data yang dilakukan melalui pengumpulan data dari hasil wawancara berupa rekaman suara dan pengamatan secara langsung.

\section{HASIL DAN PEMBAHASAN}

Pada penelitian yang kami lakukan di SMP Negeri 2 Gatak didapatkan hasil observasi mengenai keadaan lingkungan sekolah. Keadaan lingkungan di sekolah ini cukup baik, SMP N 2 Gatak dipenuhi dengan pohon pohon dan tanaman hijau sehingga udara di sekitar sekolah ini sejuk. Di depan setiap kelas juga terdapat berbagai macam bunga, wastafel untuk cuci tangan, dan tempat sampah yang dihias sedemikian rupa. Dengan alasan tersebut SMP N 2 Gatak menjadi sekolah yang terpilih di Kabupaten Sukoharjo untuk mengikuti Program Adiwiyata. Program Adiwiyata adalah salah satu program Kementerian Negara Lingkungan Hidup dalam rangka mendorong terciptanya pengetahuan dan kesadaran warga sekolah sehingga menjadi sebuah karakter peduli lingkungan dalam upaya pelestarian lingkungan hidup. Program Adiwiyata didasarkan atas dua prinsip, yaitu: 1) partisipatif, yang berarti sekolah terlibat dalam manajemen yang meliputi keseluruhan proses perencanaan, pelaksanaan dan evaluasi sesuai tanggung jawab dan peran; dan 2) berkelanjutan, yang berarti seluruh kegiatan harus dilakukan secara terencana dan terus menerus (Desfandi, 2015). Salah satu perilaku yang perlu dikembangkan bagi generasi muda bangsa adalah perilaku peduli lingkungan dan tanggung jawab. Hal tersebut didasarkan dari banyaknya masalah kerusakan lingkungan hidup yang terjadi di lingkungan. Masalah lingkungan hidup bukanlah permasalahan baru, melainkan sama dengan usia bumi ini.

Dari hasil observasi yang didapat, SMP Negeri 2 Gatak memiliki potensi untuk menjadi sekolah Adiwiyata karena memiliki kondisi lingkungan yang mendukung dan memiliki kebijakan sekolah yang berbasis pada lingkungan. Kebijakan ini bisa dilihat melalui misi SMP N 2 Gatak yaitu "Berakhlak Mulia, Unggul dalam Prestasi, 
Berwawasan Lingkungan Berlandaskan Iman dan Taqwa”. SMP N 2 Gatak juga melakukan proses pembelajaran yang melibatkan alam sekitar, misalnya pembelajaran IPA dengan materi lingkungan abiotik dan biotik yang diampu oleh Dra. Sri Indinah dilakukan di luar ruang kelas dengan tujuan agar siswa lebih mengenal lingkungannya serta dapat mengimplementasikan mata pelajaran yang dipelajari secara langsung.

Dari hasil observasi, SMP N 2 Gatak melakukan berbagai persiapan menuju sekolah Adiwiyata. Hal ini dapat dilihat dari berbagai kegiatan peduli lingkungan yang melibatkan guru dan siswa di SMP N 2 Gatak. Kegiatan yang dilaksanakan yaitu memperbanyak pepohonan di lingkungan sekolah, bukan hanya pepohonan saja tetapi juga terdapat tanaman-tanaman hias diantaranya tanaman bunga matahari, bunga mawar, lidah mertua, lili paris, dan masih banyak lagi. Kegiatan berikutnya yaitu dengan meningkatkan karakter peduli lingkungan pada siswa dengan cara mewajibkan siswa untuk untuk membawa tanaman beserta potnya, masing-masing tanaman diberi nama dan setiap siswa harus bertanggung jawab terhadap tanaman yang dibawa. Jika tanaman yang dibawa dari salah satu siswa ada yang mati maka siswa tersebut membawa kembali tanaman ke sekolah. Selain membawa dan merawat tanaman, siswa juga diarahkan bagaimana caranya untuk memanfaatkan barang-barang bekas menjadi sesuatu yang bermanfaat. Contohnya siswa dan guru bekerja sama membuat pot- pot bunga yang berasal dari botol bekas kemudian diwarnai dan diletakkan didepan kelas. Selain itu tempat sampah yang ada di SMP N 2 Gatak juga merupakan tong bekas yang di bersihkan kemudian di cat dengan warna yang menarik dan di beri gambar agar terlihat lebih indah. Selain pepohonan dan tanaman" yang banyak dijumpai di lingkungan sekolah, kami juga mendapati beberapa Bioporing yang ada dilingkungan sekolah. Bioporing adalah lubang yang berguna sebagai resapan air ketika musim hujan tiba dan berfungsi agar halaman sekolah tidak tergenang air ketika hujan.

Persiapan SMP N 2 Gatak menuju sekolah Adiwiyata dapat meningkatkan karakter peduli lingkungan pada siswa melalui berbagai kegiatan yang dilaksanakan sekolah. Rasa tanggung jawab siswa untuk menjaga lingkungan akan timbul seiring dengan berjalannya kegiatan yang dilaksanakan. Ibu Inggit Conni A, S.Pd., selaku kepala sarana dan prasarana serta guru yang ikut terlibat dalam persiapan sekolah menuju sekolah Adiwiyata menuturkan bahwa dengan adanya program Adiwiyata ini karakter kepedulian siswa meningkat dari tahun sebelumnya. Hal ini dibuktikan dengan mulai adanya kepekaan untuk menjaga sarana dan prasarana sekolah tanpa merusaknya. Walaupun masih terdapat beberapa siswa yang tidak peduli terhadap lingkungan dengan membuang sampah sembarangan. Siswa yang membuang sampah sembarangan biasanya diatasi dengan teguran oleh guru yang melihatnya. Kepala sekolah dan guru memberikan contoh teladan 
kepada siswa dengan ikut serta dalam menjaga kebersihan lingkungan, mengikuti kegiatan kebersihan, menanam pohon, serta berpakaian rapi agar menjadi contoh yang baik kepada siswa.

\section{SIMPULAN}

Berdasarkan observasi yang telah dilakukan di SMP N 2 Gatak dapat disimpulkan bahwa SMP N 2 Gatak menanamkan karakter peduli lingkungan pada siswa dengan cara mewajibkan siswa membawa dan merawat tanaman di sekolah, membuat kerajinan dari barang bekas, melaksanakan proses pembelajaran IPA di luar ruangan untuk mengenalkan siswa dengan lingkungan sekitar. Penanaman karakter ini terus ditingkatkan seiring berjalannya persiapan SMP N 2 Gatak menuju sekolah Adiwiyata. Dengan adanya program Adiwiyata sekolah lebih bersemangat dalam melakukan penanaman karakter peduli lingkungan kepada siswa. Dari pengamatan yang dilakukan oleh peneliti, kegiatan peduli lingkungan yang dilaksanakan di SMP N 2 Gatak dapat meningkatkan kepekaan siswa terhadap lingkungan.

\section{DAFTAR PUSTAKA}

Adam, Ahmad Fajarisma Budi. 2014. Analisis Implementasi Kebijakan Kurikulum Berbasis Lingkungan Hidup Pada Program Adiwiyata Mandiri di SDN Dinoyo 2 Malang. Jurnal Kebijakan dan Pengembangan Pendidikan. Vol. 2, No. 2, Hlm. 166-173.

Aini, Maisyarotul Huril. 2014. Penguasaan Konsep Lingkungan Dan Sikap Peduli Lingkungan Siswa Sma Adiwiyata Mandiri Di Kabupaten Mojokerto. Jurnal Bioedu. Vol. 3, No. 3, Hlm. 479-484.

Al-Anwari, Amirul Mukminin. 2014. Strategi Pembentukan Karakter Peduli Lingkungan Di Sekolah Adiwiyata Mandiri. Jurnal Ta'dib. Vol. 19, No. 2, Hlm. 227- 252.

Ardianti, Sekar Dwi, dkk. 2017. "Peningkatan Perilaku Peduli Lingkungan dan Tanggung Jawab Siswa Melalui Model EJAS dengan Pendekatan Science Edutainment". Jurnal Ilmiah Pendidikan Dasar. Vol 4. No 1. Hal : 1.

Azmi, Fadila dan Elfyetti. 2017. "Analisis Sikap Peduli Lingkungan Siswa Melalui Program Adiwiyata di SMA Negeri 1 Medan”. Jurnal Geografi. Vol 9. No 2. Hal : 126.

Bahrudin, Mohammad Dendy Fathurahman. 2017. "Pelaksanaan Program Adiwiyata dalam Mendukung Pembentukan Karakter Peduli Lingkungan di SMA Negeri 4 Pandeglang”. Jurnal Pendidikan Geografi. Vol 17. No 1. Hal : 27.

Desfandi, Mirza. 2015. Mewujudkan Masyarakat Berkarakter Peduli Lingkungan Melalui Program Adiwiyata. Sosio Didaktika. Vol. 2, No. 1, Hlm. 31-37.

Harlistyarintica, Yora, dkk. 2017. "Penanaman Pendidikan Karakter Cinta Lingkungan Melalui Jari Kreasi Sampah Bocah Cilik di Kawasan Parangtritis”. Jurnal Pendidikan Anak. Vol 6. No 1. Hal $: 22$. 
Iswari, Rizky Dewi \& Suyud W. Utomo. 2017. Evaluasi Penerapan Program Adiwiyata Untuk Membentuk Perilaku Peduli Lingkungan di Kalangan Siswa (Kasus: SMA Negeri 9 Tangerang Selatan dan MA Negeri 1 Serpong). Jurnal Ilmu Lingkungan. Vol. 15, No. 1, Hlm. 35-41.

Landriany, Ellen. 2014. Implementasi Kebijakan Adiwiyata Dalam Upaya Mewujudkan Pendidikan Lingkungan Hidup di SMA Kota Malang. Jurnal Kebijakan dan Pengembangan Pendidikan. Vol. 2, No. 1, Hlm. 82-88.

Lestari, Yeni. 2018. "Penanaman Nilai Peduli Lingkungan Dalam Pembelajaran Ilmu Pengetahuan Alam”. Jurnal Pendidikan Ke$S D$-an. Vol 4. No 2. Hal : 332.

Mulyana, Rachmat. 2009. Penanaman Etika Lingkungan Melalui Sekolah Peduli dan Berbudaya Lingkungan. Jurnal Tabularasa PPS Unimed. Vol. 6, No. 2, Hlm. 175-180.

Nurani, Novian Fitri., Saiful Ridlo \& Sri Mulyani Endang Susilowati. 2014. Pengembangan Modul Pendidikan Lingkungan Hidup (PLH) Berbasis Karakter Untuk Menumbuhkan Wawasan Dan Karakter Peduli Lingkungan. Unnes Journal of Biology Education. Vol. 3, No. 1, Hlm. 53-60.

Rahmawati, Ira. 2015. Upaya Pembentukan Perilaku Peduli Lingkungan Siswa Melalui Sekolah Adiwiyata Di Smp Negeri 28 Surabaya. Jurnal Kajian Moral dan Kewarganegaraan. Vol. 1, No. 3, Hlm. 71-88.

Widyaningrum, Ratna. 2016. Pembentukankarakter Peduli Lingkungan Siswa Sekolah Dasar Melalui Sekolah Peduli Dan Berbudaya Lingkungan. Jurnal Widya Wacana. Vol. 11, No. 1, Hlm. 108-116. 